\title{
ANALYSIS OF A HIGH RISE BUILDING FRAME CONSIDERING LATERAL LOAD RESISTING MEMBERS: A REVIEW
}

\author{
Mohit Kumar Prajapati \\ Assistant professor, School of Engineering Technology, Vikram University, Ujjain, India
}

\begin{abstract}
The advancement of high strength structural materials just as the presentation of dominating improvement strategies gave a lift in the advancement of tall constructions. As the tallness of the construction builds, they become logically helpless against wind load and seismic burden. The resistance of tall constructions to horizontal burdens is the essential determinant in the detailing of new fundamental structural systems that create by the consistent undertakings of structural architects to continue expanding the structure tallness while keeping the redirection inside commendable purposes of restriction and restricting the proportion of materials. In this proposed work a logical investigation will be consider on such frameworks like outrigger framework with center shear divider and hex lattice frameworks, to decide their structural proficiency in moving the horizontal loads securely to the ground.

In this investigation we are giving audit of researches identified with examination of tall building structures.
\end{abstract}

Keywords: Structural Analysis, Forces, Deflection, Lateral Forces, Etabs

Cite this Article: Mohit Kumar Prajapati, Analysis of a high rise building frame considering lateral load resisting members: A Review, International Journal of Civil Engineering and Technology (IJCIET), 12(3), 2021, pp. 1-4.

https://iaeme.com/Home/issue/IJCIET?Volume=12\&Issue $=3$

\section{INTRODUCTION}

Throughout the entire existence of constructions, possibly nothing is more stunning than the human objective to make dynamically tall designs. Diverse social and monetary components, for instance, relocation of individuals from to metropolitan zones searching for better lifestyle and openings for work, the addition in land esteems in metropolitan districts and higher populace thickness, have incited a mind boggling increment in the quantity of tall constructions everywhere on the world. As the tall construction is ideal to land use procedure in present time it can save a huge load of land, consequently the skylines of the world's metropolitan territories are unendingly being penetrated by specific and conspicuous tall designs as extraordinary as mountain goes, and accomplishing more stature continues being the test and objective. Nonetheless, there are some unimaginable difficulties which are to be looked by the architect 
consistently to make these constructions a reality. Out of numerous difficulties, one is that of parallel burdens for example seismic burden and wind load.

Daliya et. al. (2019) the exploration paper presented an examination of hexagrid system coordinated by using assessment and design programming, ETABS. A standard floor plan $36 \mathrm{~m}$ $\mathrm{x} 36 \mathrm{~m}$ and irregular floor plans shaped as $\mathrm{C}, \mathrm{L}$ and $\mathrm{T}$ were thought of, each fundamental part was organized by IS 456:2000. G+30, G+40 and G+50 stories models are considered to take a gander at the presentation by stature. Seismic boundaries were considered from 1893-2002. Dead and live loads were considered by Indian Standards. Results communicated that as the height of the construction extends movement also increases. The show reason for the $T$ shape and L shape plan irregularity was more like each other. Time interval increases with increase in height of the construction. Base shear was least aside from the $\mathrm{C}$ shaped model.

Manzoor et. Al. (2019) the exploration paper presented a sensible examination made on the structural framework, for instance, the outrigger system with focus shear divider and hexagrid systems, to choose their essential adequacy in moving the sidelong loads safely to the ground. An assessment of outrigger system with focus shear divider and a hexagrid system was made on a 38-story building strengthened strong construction by using standard pack ETABS 2016 by taking a gander at changed boundaries, for instance, Maximum Story Displacement, Maximum Story Drift and Story Shears. The end communicated that the hexagrid system is best as it has least sidelong expulsion and it gives a better designing appearance than the construction.

Kachchhi et. al. (2019) the exploration paper think about a parametric examination of a symmetric structure, displaying a 10 story structure and the investigation of the model was finished utilizing ETABS V2017 for structural frameworks in particular Shear dividers, Belt Truss, Outrigger, Diagrid, Staggered Truss and a customary Frame. Construction investigation was done viewed as Dead burden, Live burden, Seismic burden and Wind load. Static and Response range examination was accomplished for performing tremor loads where the model was considered on seismic zone V. The outcomes displayed that Displacements on each story and story drift was less in Diagrid systems in X-Direction interestingly with other equal burdens contradicting structure. Story Displacement on each story and story drift were less in Staggered Truss systems in Y-Direction when appeared differently in relation to other equal weight restricting structure.

Altaf et. al. (2018) the exploration paper displayed relative examination on fundamental packaging building, diagrid essential system building, pentagrid structural system building and hexagrid essential structure building.

The end incited that Maximum story displacement in Diagrid structure was less when diverged from other fundamental systems like pentagrid and hexagrid structure. Greatest story floats in Diagrid structure was less when differentiated to pentagrid and hexagrid essential system. Base shear in Diagrid structure was less when differentiated thane pentagrid and hexagrid structural system alongside its time frame.

Deepak et. Al. (2019) the exploration paper introduced even hexagrid plan which intended to explore the ideal edge and geography of inclining people in a hexagrid plot using restricted part examination and to think about the assistant properties of hexagonal designs to differentiate their possible capability and the standard construction.

The end displayed diagrid structure reduces twisting second which in outcomes lessens fortification essential. Even removing can be restricted by using diagrids. In view of slanting segments on its periphery, diagrid showed better security from equal burdens and internal portions get free and pass on gravity loads. While in common construction both interior and outer segment was planned for both gravity and equal burden. The diagrid arrangement 
diminished in the scope of edge bars at substitute floors, therefore decreasing the bar forces at exchange floors.

Thomas et. al. (2018) the creator drove a seismic examination of the construction for hexagrid structures with the vertical and level course of the hexagrid module. A 60 story steel structure with symmetric floor plan by using same the volume of steel was arranged and an equivalent static examination was guided using SAP 2000 programming to ideal module size. The outcomes communicated with the development in module size, the evacuating and buoy assessments of vertical hexagrid models are lessening. So extending the module size gave dynamically stable constructions in vertical hexagrid plan. With the development in module size, the migration and buoy assessments of level hexagrid models are extending. So growing the module size diminishes adequacy in level hexagrid plan. The gravity load was coursed correspondingly in vertical hexagrid models. The level Hexa-systems was found to take a higher gravity load than the vertical Hexa-frameworks.

Subramani and Murali (2018) the exploration paper focused on assessment of the presentation of multi outrigger structural framework for a ten story developing with static and dynamic investigations of different math utilizing ETABS program. The presentation assessment of the tall construction for unmistakable calculation was performed to locate the fitting limit of outrigger contraption and belt uphold with the guide of the utilization of equal burden. Time history assessment for floor improvement bits of knowledge of the ten-story building version was finished. The evaluation included sidelong evacuating; stories acknowledge the status quo and base shear for static and dynamic stacking. The results contemplated that bundled tube was exceptional seismic control for continuously over the top upward push symmetric designs. As time records were viable technique, used for seismic appraisal which gave a most extraordinary higher check to the security of design investigation and arranged by strategy for framework dictated by technique for IS code.

Shaikh et. al. (2017) the exploration paper introduced relative aftereffects of diagrid and outrigger structural framework for elevated structure of tallness $108 \mathrm{~m}$ exposed to parallel breeze load. The examination included unmistakable construction models with the shear divider structure, diagrid system and outrigger structure. By using Gust factor system as indicated by IS 875 (Part-3)- 1987, the sidelong wind load was controlled by thinking about unique 'close by wind' response. Thus, this examination dissected different models by varying the purpose of propensity and changing the region of the outrigger. Assessment of examination results was made with respect to popular narrative expulsion, essential forces, material use and period. The outcomes communicated that the course of action line diagrid system in tall constructions improved the structural immovability and made the essential structure fruitful under equal loads similarly as they were viable in decreasing the flat evacuating. The popular narrative evacuating of Building with 4-Story diagrid module $\left(67.38^{\circ}\right.$ propensity) decreases to $10 \%$ when diverged from the Building with two outriggers @ $0.33 \mathrm{H}$ and $0.66 \mathrm{H}$ communicating that for tall construction, line diagrid system was the worthwhile structural structure. The usage of steel material for outrigger essential structure by $17 \%$ higher than the diagrid assistant system. Consequently it will in general be assumed that for raised constructions, plan of diagrid fundamental system will be moderate. The hour of the diagrid structure was less when stood out from the outrigger structure $(2.1 \mathrm{Sec})$ provoking the end that the diagrid essential system was significantly stiffer than the outrigger and shear divider structural system. Diagrid structure gave a dynamically useful system in designing organizing similarly as higher structural capability for raised constructions. 
Analysis of a high rise building frame considering lateral load resisting members: A Review

\section{CONCLUSION}

ETABS is advance examination apparatus for structural investigation.

- Researchers discovered that sidelong dependability in a design limits the twisting second and forces created because of burdens and its age which brings about expansion in construction existence with steadiness and security.

- It is seen that for seismic power resistivity sidelong opposing individuals are important to give safe plan.

\section{REFERENCES}

[1] Divya M. S. and B. Saraswathy, [Comparative Analysis Of High Rise Steel Building With Hexagrid, Diagrid And Conventional Structural System], International Research Journal of Engineering and Technology (IRJET), Volume: 04 Issue: 04 | Apr -2017.

[2] Diya Susan Ebin and D. Arul Prakash, [Study On Structural Behaviour Of Hexagrid Structural Systems In Multi Storey Buildings], Int. J. Chem. Sci.: 14(S1), 2016, 330-340, ISSN 0972$768 X$.

[3] Mathew Thomas and Alice Mathai, [Seismic Analysis of Hexagrid Structure with Various Patterns], International Research Journal of Engineering and Technology (IRJET), Volume: 05 Issue: 04 | Apr-2018.

[4] D. R shambale and A.A hamane, [Comparative Study Of Wind Analysis Of High Rise Building With Diagrid And Outrigger Structural System Using Gust Factor Method], International Journal of Novel Research and Development, Volume 3, Issue 7 July 2018 | ISSN: 2456-4184.

[5] Deepak Laata and MayankMehandiratta, [Results and Analysis of Hexagrid and Diagrid Systems in Multi Storey Buildings], International Journal of Science, Engineering and Technology, ISSN (2348-4098), 2019.

[6] Jateen M. Kachchhi, Snehal V. Mevada\& Vishal B. Patel, [Comparative Study Of Diagrid Structure With Other Structural Systems For Tall Structures], Global Journal Of Engineering Science And Researches, ISSN 2348 - 8034, Impact Factor- 5.070, April 2019.

[7] Mathew Thomas and Alice Mathai, [Seismic Analysis of Hexagrid Structure with Various Patterns], International Research Journal of Engineering and Technology (IRJET), Volume: 05 Issue: 04 | Apr-2018.

[8] Mohsen Rostami, Fatemeh Gorjisinaki and AbdolrezaS.Moghadam, [Evaluation of new Hexagrid structural system in bionic high-rise buildings], 5Th international conference of Research in Science and Technology, 15th November 2016. 